\title{
Mediation of inducible nitric oxide and immune-reactive lysozymes biosynthesis by eicosanoid and biogenic amines in flesh flies
}

\author{
Amr A. Mohamed ${ }^{\dagger}$, Mona M. Ali ${ }^{\dagger}$, Moataza A. Dorrah \\ and Taha T. M. Bassal* \\ Department of Entomology, Faculty of Science, Cairo University, Giza, PO Box \\ 12613, Egypt
}

(Accepted 2 October 2017)

\begin{abstract}
Nitric oxide (NO) plays various roles in insect immunity: as a cytotoxic component and as a signalling molecule; and immune-reactive lysozymes (IrLys) provide a first line of humoral immune functions against invading bacteria. Although there is considerable literature on eicosanoid and biogenic monoamine actions on insect immunity, there is no information on the role(s) of these chemicals in inducing NO and IrLys. We addressed this gap by challenging third instar Sarcophaga (Liopygia) argyrostoma (RobineauDesvoidy) with the Gram-positive bacterium Micrococcus luteus. Here, we report that bacterial challenge induces elevation of $\mathrm{NO}$ and IrLys concentrations in haemocytes and in the fat body. The plasma pool content is comparatively low. Eicosanoid biosynthesis inhibitors (EBIs) lead to suppression of both NO and IrLys levels. Control larvae have low constitutive levels of $\mathrm{NO}$ and lysozyme concentrations. Octopamine (OA) elicits elevation of NO and IrLys concentrations. A similar effect is obtained by 5-hydroxytryptamine (5HT) for NO. These data indicate immune-mediating roles of eicosanoids, OA and 5-HT in NO and IrLys activities.
\end{abstract}

Key words: Nitric oxide, lysozymes, eicosanoids, biogenic monoamines, Sarcophaga

\section{Introduction}

Nitric oxide (NO) is a highly reactive unstable free radical metabolite. It is generated through oxidation of the amino acid L-arginine to L-citrulline, a reaction catalysed by NO synthase (NOS). This enzyme is found in vertebrates as two main types: constitutive (cNOS) and inducible (iNOS) (Alderton

\footnotetext{
*E-mail: taha@sci.cu.edu.eg

${ }^{\dagger}$ Both authors contributed equally to this work.

Authors' contributions

Conceptualization: TTMB, MAD and AAM. Data curation: TTMB and AAM. Formal analysis: MMA, AAM and MAD. Funding acquisition: MMA and AAM. Investigation: AAM and MMA. Methodology: TTMB, AAM and MAD. Resources: MAD, MMA and AAM. Software and Statistics: AAM. Supervision: TTMB and MAD. Validation: TTMB, AAM and MAD. Visualization: MMA and AAM. Writing - original draft: TTMB and AAM. Writing review and editing: TTMB and AAM.
}

et al., 2001). In some insects NO is inducibly synthesized by the iNOS in response to infections, as in Anopheles gambiae (Hillyer and Estévez-Lao, 2009), Anopheles stephensi (Luckhart et al., 1998) and Rhodnius prolixus (Whitten et al., 2001). In immune-reactive insects, $\mathrm{NO}$ is frequently produced by activated cells in association with the reactive oxygen intermediates (ROI) ${ }^{\bullet} \mathrm{O}_{2}^{-}$and $\mathrm{H}_{2} \mathrm{O}_{2}$. These ROI, particularly $\mathrm{H}_{2} \mathrm{O}_{2}$, are activators or secondary messengers of NF- $\kappa \mathrm{B}$ (Nappi et al., 2000). To initiate cytotoxic activity, $\mathrm{NO}$ reacts with both ${ }^{\circ} \mathrm{O}_{2}^{-}$to form peroxynitrite $\left(\mathrm{ONOO}^{-}\right)$(Halliwell and Gutteridge, 1999) and $\mathrm{H}_{2} \mathrm{O}_{2}$ to form the highly reactive hydroxyl radical $\left({ }^{\bullet} \mathrm{OH}\right)$ (Hogg et al., 1992). At physiological $\mathrm{pH}$, both $\mathrm{NO}$ and $\mathrm{H}_{2} \mathrm{O}_{2}$ can readily diffuse from their tissues of origin to damage lipids, proteins and DNA (Nappi et al., 2000). Therefore, NO is toxic to a wide-spectrum of pathogens, including bacteria, fungi, protozoa and viruses (Colasanti 
et al., 2002; Faraldo et al., 2005). Also, NO performs a signalling function, as indicated in Drosophila melanogaster, in the induction of host defences to Gram-negative bacteria (Foley and O'Farrell, 2003), in neuroinflammatory responses (Ajjuri and O'Donnell, 2013) and in chemosensory transduction and functioning of the odorant receptor cells in the flesh fly Neobellieria bullata (Wasserman and Itagaki, 2003).

Lysozymes (E.C. 3.2.1.17), 1,4-N-acetylmuramidases, catalyse cleavage of peptidoglycan's $\beta-1,4-$ glycosidic bond between the alternating linked residues of $N$-acetylmuramic acid (MurNAc) and $N$ acetylglucosamine (GlcNAc) that often comprise a principal component of bacterial cell wall, resulting in its depolymerization (Mohamed et al., 2013). Lysozymes are one of the components of the insect humoral immune system that respond to bacterial challenge (Hillyer, 2016) and are upregulated upon infection (Mohamed et al., 2016). This upregulation was reported to take place through injection of the bacterial cell wall components, peptidoglycan (PGN) and lipopolysaccharides (LPS) or fungal $\beta$ 1,3-glucans such as laminarin (Morishima et al., 1995; Mohamed et al., 2013).

Immune mediators of insects play critical roles in relaying immune signals from non-self-recognition to immune effectors, such as fat body and haemocytes (Gillespie et al., 1997). Among these mediators, the eicosanoids are oxygenated derivatives of arachidonic acid (AA) and other C20 polyunsaturated fatty acids. The chemistry and biosynthesis pathways of eicosanoids have been detailed elsewhere (Stanley, 2000). Briefly, cyclooxygenases (COXs) oxygenate free AA to form prostaglandins (PGs), while hydroxyeicosanoids and leukotrienes (LTs) are produced from AA via lipoxygenases (LOXs), and epoxytrienoic acid formed by P450 epoxygenases. Eicosanoids act in mediating cellular immune responses in insects (Stanley and Kim, 2014) and key steps in humoral immunity (such as cell lysis of oenocytoids releasing stored PPO) (Shrestha and Kim, 2008, 2009; Shrestha et al., 2015). Additionally, biogenic monoamines, octopamine (OA; chemically related to norepinephrine [NE]) and serotonin (5-hydroxytryptamine [5-HT]) mediate the cellular immune reactions in some, and possibly all, insects (Baines et al., 1992; Dunphy and Downer, 1994; Kim et al., 2009; Qi et al., 2016).

Larval filth-breeding flies like the flesh fly Sarcophaga argyrostoma (Robineau-Desvoidy) (Diptera: Sarcophagidae) live in highly bacteria-contaminated habitats and are constantly exposed to infection. We hypothesized that flesh flies express NO and lysozymes in response to bacterial-challenge and that eicosanoids and biogenic monoamines (BMAs) mediate these responses. In this paper, we investig- ate the roles of eicosanoids, using eicosanoid biosynthesis inhibitors (EBIs) and BMAs as mediators of $\mathrm{NO}$ and lysozyme biosynthesis.

\section{Materials and methods}

\section{Insects}

The stock colony of flesh fly S. argyrostoma originated from field-collected flies and maintained in the laboratory at $27 \pm 2{ }^{\circ} \mathrm{C}$ and fluctuating $\mathrm{RH}$. Adult flies were confined in rearing cages $\left(40 \times 40 \times 40 \mathrm{~cm}^{3}\right)$ supplied with approximately $250 \mathrm{~g}$ fresh meat block as a larviposition-, feeding- and rearing-medium. Sucrose solution (5\%), used as a food supplement, was also offered to adults. Detailed descriptions of $S$. argyrostoma rearing, temperature regimesdependent development and bionomics are given in Grassberger and Reiter (2002).

\section{Chemicals}

Chemicals were purchased from Sigma-Aldrich (St. Louis, MO, USA), except phenidone, which was purchased from Santa Cruz Biotech., USA. Bacteriological media were purchased from Oxoid (Basingstoke, UK). Other routine chemicals were obtained from Acros organics (Morris Plains, NJ, USA).

\section{Bacteria}

The Gram-positive bacteria Micrococcus luteus (=Microccus lysodeikticus ATCC No. 4698; Sigma) was used for immune challenge. The bacteria were cultured in liquid Luria Bertani (LB) broth (tryptone $1 \%$; yeast extract $0.5 \%$; $\mathrm{NaCl} 0.5 \%$; $\mathrm{pH}$ adjusted to 7 with $1 \mathrm{~N} \mathrm{NaOH}$ ), grown aerobically at $30{ }^{\circ} \mathrm{C}$ for $24-48 \mathrm{~h}$ in $250 \mathrm{ml}$ shake flasks set at $200 \mathrm{rpm}$. The cells were harvested by centrifugation at $5200 \times g$ for $15 \mathrm{~min}$. The bacterial pellets were initially washed in $0.01 \mathrm{M}$ EDTA pH 7.0, and $0.15 \mathrm{M} \mathrm{NaCl}$. The cells were pelleted again and then suspended in sterile phosphate buffered saline ( $\mathrm{pH} 7.4)$. In all infection experiments, larvae were injected individually with $2 \mu \mathrm{l}$ suspension of $2.56 \times 10^{8}$ heat-killed bacterial cells $/ \mathrm{ml}\left(\mathrm{OD}_{600}=0.32\right)$. The structural integrity of the bacterial cells after the boiling treatment (15 $\mathrm{min}$ ) was confirmed by light microscopy and Gram staining (Prescott et al., 1993).

\section{Preparation of plasma, haemocyte lysate and cell-free fat body extract}

Haemolymph was collected from the third instars of S. argyrostoma. The insects were placed in a Petri dish on ice, and their body surface sterilized with $70 \%$ ethanol. Haemolymph was obtained by 
puncturing the larval abdomen with a sterile needle. The oozing haemolymph was immediately collected and pooled into sterile, chilled $2 \mathrm{ml}$ Eppendorf tubes containing sterilized anticoagulating citrate-EDTA buffer ( $30 \mathrm{mM}$ trisodium citrate, $26 \mathrm{mM}$ citric acid, $10 \mathrm{mM}$ EDTA, $100 \mathrm{mM}$ glucose, $62 \mathrm{mM} \mathrm{NaCl}$ and $0.05 \mathrm{mM} \mathrm{CaCl}_{2}, \mathrm{pH} 4.6$ ) (Söderhäll and Smith, 1983). One $\mathrm{ml}$ of haemolymph was collected from ca. 150 larvae to avoid contamination with fat body tissues. (Taking a small amount of haemolymph from each larva helps to prevent contamination.) The haemolymph was then centrifuged at $7500 \mathrm{xg}$ and $4{ }^{\circ} \mathrm{C}$ for $5 \mathrm{~min}$, and the resulting supernatant (plasma) used for NO and lysozyme assays. The pellet obtained after centrifugation, containing haemocytes, was washed twice with $2 \mathrm{ml}$ of sodium cacodylate buffer $\left[0.01 \mathrm{M}\left(\mathrm{CH}_{3}\right)_{2} \mathrm{AsO}_{2} \mathrm{Na} \cdot 3 \mathrm{H}_{2} \mathrm{O}, 5 \mathrm{mM} \mathrm{CaCl}_{2}\right.$ and 0.25 $\mathrm{M}$ sucrose, $\mathrm{pH}$ 7.0]; Leonard et al., 1985] before homogenization with a glass-Teflon homogenizer in $0.01 \mathrm{M}$ sodium cacodylate buffer containing $5 \mathrm{mM} \mathrm{CaCl}_{2}$. The haemocyte homogenate was then centrifuged at $16,900 \mathrm{xg}$ at $4{ }^{\circ} \mathrm{C}$ for $15 \mathrm{~min}$ and the resulting supernatant (haemocytes lysate) used for assaying concentrations of nitrite ion and lysozymes.

For fat body isolation, cleaned chilled third instars were dissected in Petri dishes under sterile ice-cold physiological saline $(172 \mathrm{mM} \mathrm{KCl}, 68 \mathrm{mM}$ $\mathrm{NaCl}_{2}, 5 \mathrm{mM} \mathrm{NaHCO}$, pH 6.1, osmolality 420 mOsm) (Vilcinskas and Matha, 1997). Fat body tissues were excised under a stereomicroscope by cutting off the anterior and posterior larval ends with a fine forceps and gently squeezing the larval body. The fat body was isolated at 2, 6, 12, 24, 48 and $72 \mathrm{~h}$ from control and treated larval batches from 10 larvae per individual treatment condition, washed in physiological saline, transferred into sterile, chilled Eppendorf tubes containing $1 \mathrm{ml}$ of physiological saline and frozen in liquid nitrogen. The frozen fat body was thawed and homogenized with a Teflon pestle. The homogenate was centrifuged at $20,000 \mathrm{xg}$ and $4{ }^{\circ} \mathrm{C}$ for $15 \mathrm{~min}$ to remove cell debris and the supernatant was collected, aliquoted and stored at $-20{ }^{\circ} \mathrm{C}$ until use. Total protein in the samples was estimated according to Bradford (1976) with bovine serum albumin as a standard.

\section{Injection of immune modulators}

The third instar larvae were washed with distilled $\mathrm{H}_{2} \mathrm{O}$ and surface-sterilized by swabbing with $70 \%$ ethanol, then divided into four groups: (i) saline-injected larvae (as control), (ii) larvae injected with bacteria, (iii) larvae injected with each compound separately and (iv) larvae injected with bacteria combined with one of the test compounds. Two $\mu$ l of the EBIs of dexamethazone (Dex: $(11 \beta, 16 \alpha)-9-F l u o r o-11,17,21-$ trihydroxy-16-methylpregna-1,4-diene-3,20-dione; phospholipase A2 [PLA2] inhibitor; water soluble preparation - $0.05 \mathrm{mg} / \mathrm{ml} \mathrm{H}_{2} \mathrm{O}$ ), ibuprofen (lbu: 2(4-Isobutylphenyl) propanoic acid; COXs inhibitor $-4 \mathrm{mg} / \mathrm{ml}$ of $70 \% \mathrm{EtOH}$ ) and phenidone (Phe: 1-phenylpyrazolidin-3-one; LOXs inhibitor - 0.05 $\mathrm{mg} / \mathrm{ml} \mathrm{H}_{2} \mathrm{O}$ ), were injected into the haemocoel of the third instar larvae. The same procedure was conducted for the BMAs octopamine (OA: 4-(2-amino-1-hydroxyethyl) phenol hydrochloride - $0.20 \mathrm{mg} / \mathrm{ml} \mathrm{H}_{2} \mathrm{O}$ ) and 5-hydroxytryptamine (5-HT: 3-(2-aminoethyl)-1H-indol-5-ol - $0.30 \mathrm{mg} / \mathrm{ml}$ $\mathrm{H}_{2} \mathrm{O}$ ). The applied concentrations were those giving optimum effect and 50\% mortality $\left(\mathrm{LC}_{50}\right)$. The latter concentration was determined with probit analysis (Finney, 1971). Control larvae were injected with $2 \mu \mathrm{l}$ saline.

\section{NO concentration assay}

$\mathrm{NO}$ was determined by comparative measurements of the nitrite ion $\left(\mathrm{NO}_{2}^{-}\right)$concentration. Nitrite ion concentration was measured spectrophotometrically based on the Griess reagent ( $1 \%$ sulfanilamide in $5 \% \mathrm{H}_{3} \mathrm{PO}_{4}, 0.1 \mathrm{~N}$-1-naphthylethylenediamine dihydrochloride in $\mathrm{H}_{2} \mathrm{O}$ ) (Green et al., 1982). Equal parts of the two solutions were mixed (1:1 ratio, $\mathrm{vol} / \mathrm{vol})$, kept chilled and used within $12 \mathrm{~h}$. One volume of the sample was mixed with 1 volume of the Griess reagent, followed by $10 \mathrm{~min}$ incubation at room temperature. Absorbance of test samples was read at $540 \mathrm{~nm}$ against a blank containing all reaction components except the insect tissue, and was then converted to $\mu \mathrm{M}$ nitrite based on a standard curve with a linear positive correlation between optical density (OD) and nitrite ion $\left(\mathrm{NaNO}_{2}\right)$ concentration. The concentration was expressed as $\mu \mathrm{M} \mathrm{NO}_{2}^{-} / \mathrm{mg}$ protein.

\section{Lysozyme concentration assay}

Lysozyme concentration (lysozyme-type antibacterial activity against $M$. luteus whole cells as a substrate) was determined according to the method of Peeters and Vantrappen (1977). Lysoplates were prepared by dissolving $0.01 \%$ agarose in phosphatebuffered saline (PBS, $\mathrm{pH}$ 6.3) at $100{ }^{\circ} \mathrm{C}$. A uniform suspension of $0.5 \mathrm{mg}$ of $\mathrm{M}$. luteus in $5 \mathrm{ml}$ saline was added to $1 \mathrm{~L}$ of agarose and mixed well. The mixture was poured into plates at $4 \mathrm{~mm}$ thickness, left to cool and $2 \mathrm{~mm}$ diameter wells in $4 \times 4$ rows and $15 \mathrm{~mm}$ apart made in agarose with a cork borer. The wells were filled with $25 \mu \mathrm{l}$ of each of the tested plasma, haemocyte lysate or fat body extract. The plates were left at room temperature for 12-16 h. The diameters of the clear zones were measured. A standard curve with linear positive correlation was 
prepared between lysozyme concentration of hen egg white lysozyme (HEWL) and diameter (mm) of the clear zones. The concentration of the tested lysozymes was calculated as $\mu \mathrm{g}$ HEWL/mg protein.

\section{Statistical analysis}

Significant treatment effects were affirmed for all experiments by analysis of variance with $P<0.05$ (unless otherwise stated). Where appropriate, protected least significant difference (LSD) test was executed to separate the means. Multiway ANOVA (MANOVA) was used to examine the effects of experimental time, treatments and tissue types on concentration of the studied immune molecules. Data were expressed as means \pm SE. Regression analysis and correlation coefficients were used to fit the relationships between the variables. All statistical analyses were performed using IBM SPSS Statistics for Windows (Version 22.0. Armonk, NY: IBM Corp., USA).

\section{Results}

\section{Toxicity analysis}

We measured the influence of three EBIs and two BMAs on the activities of NO and lysozymes in response to bacterial challenge. Toxicologically, both Dex and Phe were the most potent EBIs studied in $S$. argyrostoma third instars with $\mathrm{LC}_{50}$ of $0.05 \mathrm{mg} / \mathrm{ml}$. These two compounds were about 4, 6 and 80 times more toxic than $\mathrm{OA}$, Phe and $\mathrm{Ibu}$, respectively, at the level of $\mathrm{LC}_{50}$. The least toxic was Ibu with $\mathrm{LC}_{50}$ of $4.08 \mathrm{mg} / \mathrm{ml}$. The order of toxicity of the tested compounds in a descending order, based on the $\mathrm{LC}_{50}$, was Dex $=$ Phe $>\mathrm{OA}>5-\mathrm{HT}>$ Ibu (Appendix S1). Physiologically, subsequent to inhibitor application (individually or coupled), compared to relevant controls, experimental larvae exhibited significantly reduced NO and lysozyme activities in response to bacterial challenge, as can be seen in Figs. 1 and 2. The pharmaceutical EBIs exert separate actions in eicosanoid biosynthesis pathways. For instance, Dex inhibits PLA2 and exerts other actions, including influence on gene expression. Ibu inhibits COXs, the first step in eicosanoid biosynthesis, while Phe is a dual LOXs/COXs inhibitor. On the other hand, the BMAs OA and 5-HT enhanced the immune functions in terms of $\mathrm{NO}$ and lysozyme activities, a subject of subtle interpretations, detailed later.

\section{Nitric oxide and modulating actions of EBIs and BMAs}

In all experiments in which third instar $S$. argyrostoma were treated with the different tested EBIs, Dex, Ibu and Phe, almost yielded similar results; that is, inhibitor treatments led to reductions or depletion in concentrations of $\mathrm{NO}$ with time progression (LSD, $P<0.001$ ). We chose $6 \mathrm{~h}$ PI as an optimum biosynthetic time to establish the main findings (Fig. 1). (The whole dataset is given in Appendix S2A.) However, treatment with BMAs enhanced the biosynthesis of NO, measured in terms of nitrite ion concentration (NO) (Fig. 1 and Appendix S2A).

\section{Constitutive NO levels}

A constitutive low level of $\mathrm{NO}$ has been observed in tissues of the saline-injected larval S. argyrostoma (negative controls), with no fixed pattern over time, with levels in a descending order haemocytes $>$ fat body>plasma (ca. 4, 0.6 and $0.3 \mu \mathrm{M} \mathrm{NO} \mathrm{NO}_{2}^{-} / \mathrm{mg}$ protein, respectively). These values were elevated by amounts of NO post-challenge with M. luteus (positive control). This increase reached maximal values of $c a 25,2$ and $1 \mu \mathrm{M} \mathrm{NO}_{2}^{-} / \mathrm{mg}$ protein in haemocytes, fat body and plasma, respectively, after various time intervals in these tissues, i.e. 24, 6 and $12 \mathrm{~h}$ post-injection (PI), respectively (Appendix S2A). However, NO concentration decreased with increase in time PI.

\section{Immune-suppressive actions of EBIs on NO}

$\mathrm{NO}$ in the fat body decreased slowly in larvae treated with EBIs (Dex, Ibu and Phe) with the increase in the experimental period PI (up to $72 \mathrm{~h}$ ) with either $M$. luteus alone or in combination with Dex, Ibu or Phe. However, NO increased up to 24 and $12 \mathrm{~h}$ PI with M. luteus combined with Ibu and Phe, respectively, then followed by a continuous decline (Appendix S2A). Maximum concentration of $1.08 \mu \mathrm{M}$ nitrite/mg protein was obtained after $6 \mathrm{~h}$ of treatment with $M$. luteus combined with Ibu. In all treatments, combined treatment (EBI $+M$. luteus) induced significant elevation of $\mathrm{NO}$ compared to individual treatment. Additionally, combinedtreatment larvae showed significant increase in NO levels compared to non-treated (negative and positive control) larvae (Fig. 1).

A similar pattern of concentration criteria occurred in NO of the haemocytes and plasma. There was, generally, a gradual decline in the NO with the progression of time post-treatment. NO significantly increased in treated larvae challenged with M. luteus combined with either Dex, Ibu or Phe compared to treatment only with any of these EBIs. Maximum NO of haemocytes was obtained after $12 \mathrm{~h}$ of treatment with $M$. luteus combined with Phe; while maximum NO concentration of plasma was obtained after $6 \mathrm{~h}$ of treatment with M. luteus combined with $\mathrm{Ibu}$. The highest $\mathrm{NO}$ was attained in the haemocytes, followed by fat body (Fig. 1). NO 


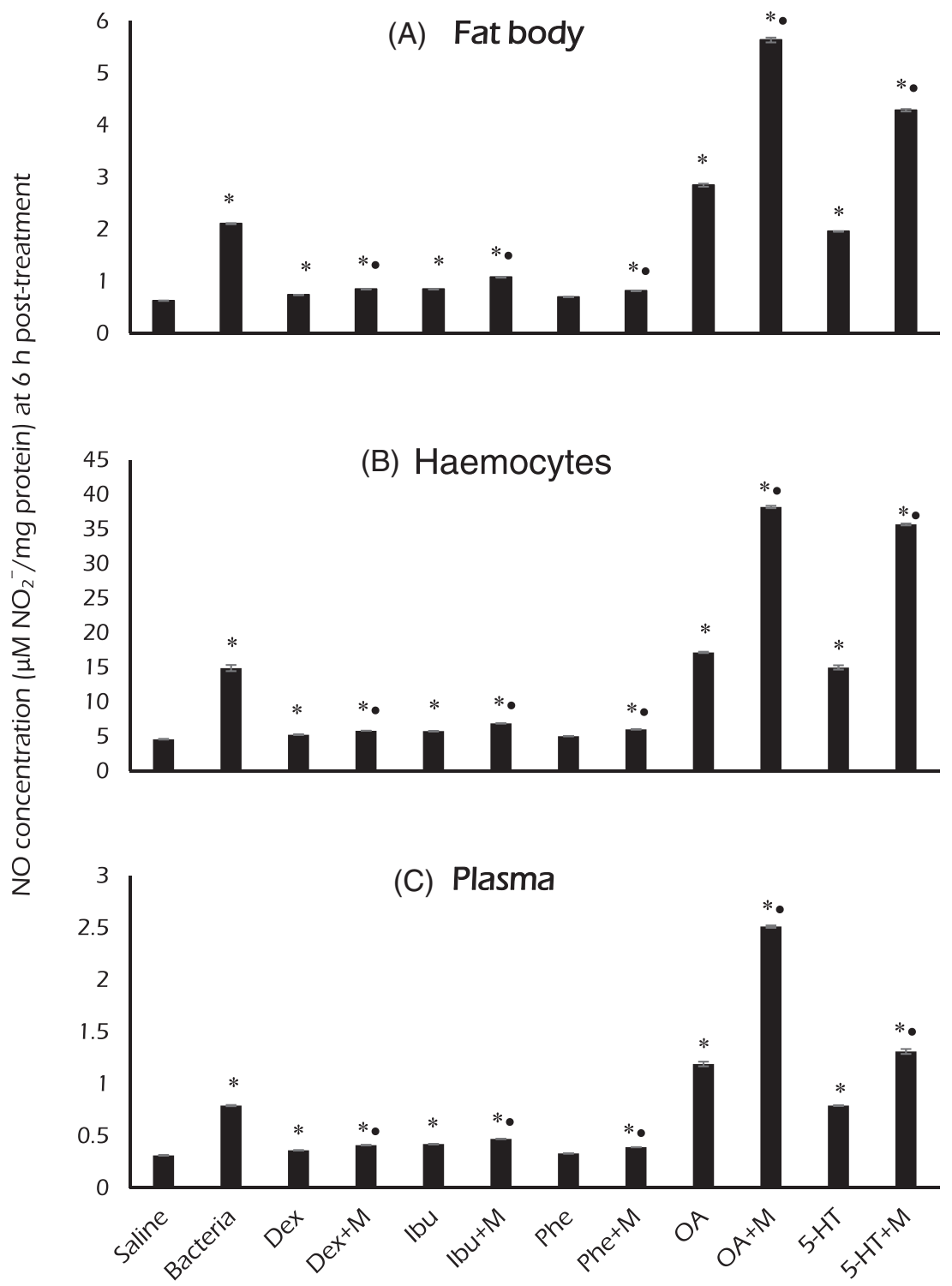

Fig. 1. Nitric oxide concentrations, expressed as $\mu \mathrm{M}$ nitrite/mg protein, in (A) fat body, (B) haemocytes and (C) plasma of third instar Sarcophaga argyrostoma post-injection with Micrococcus luteus, either alone or in couple with an EBI (Dex, Ibu or Phe) or with a BMA (OA or 5-HT) at $6 \mathrm{~h}$ PI. Values are presented as mean \pm SE $(n=3)$. *significant differences in comparison with the saline-injected larvae at $P<0.05$; ${ }^{*}$ significant differences in comparison to the corresponding group of the larvae treated with chemical alone.

of treated larvae was higher $(P<0.05)$ than that of control larvae.

\section{Immune-enhancing actions of BMAs on NO}

There was no change in the concentration of the fat body NO after treatment of S. argyrostoma third instars with the biogenic monoamine $\mathrm{OA}$ in all the experimental periods. However, NO concentration increased up to $6 \mathrm{~h}$ of treatment with both M. luteus combined with $\mathrm{OA}$ and individual treatment with 5-HT, and increased up to $12 \mathrm{~h}$ PI with M. luteus combined with 5-HT, after which the concentration began to decrease (Appendix S2A). In all treatments, combined treatment with M. luteus and the BMAs (OA and 5-HT) significantly enhanced the NO concentration compared to treatment only with the monoamines. Treated larvae showed a significant increase in the concentration of NO compared to control larvae (Fig. 1). There was no change in the concentration of NO of the haemocytes and plasma after treatment of $S$. argyrostoma with OA. Combining $M$. luteus with either OA or 5-HT significantly increased the haemocytes or plasma 


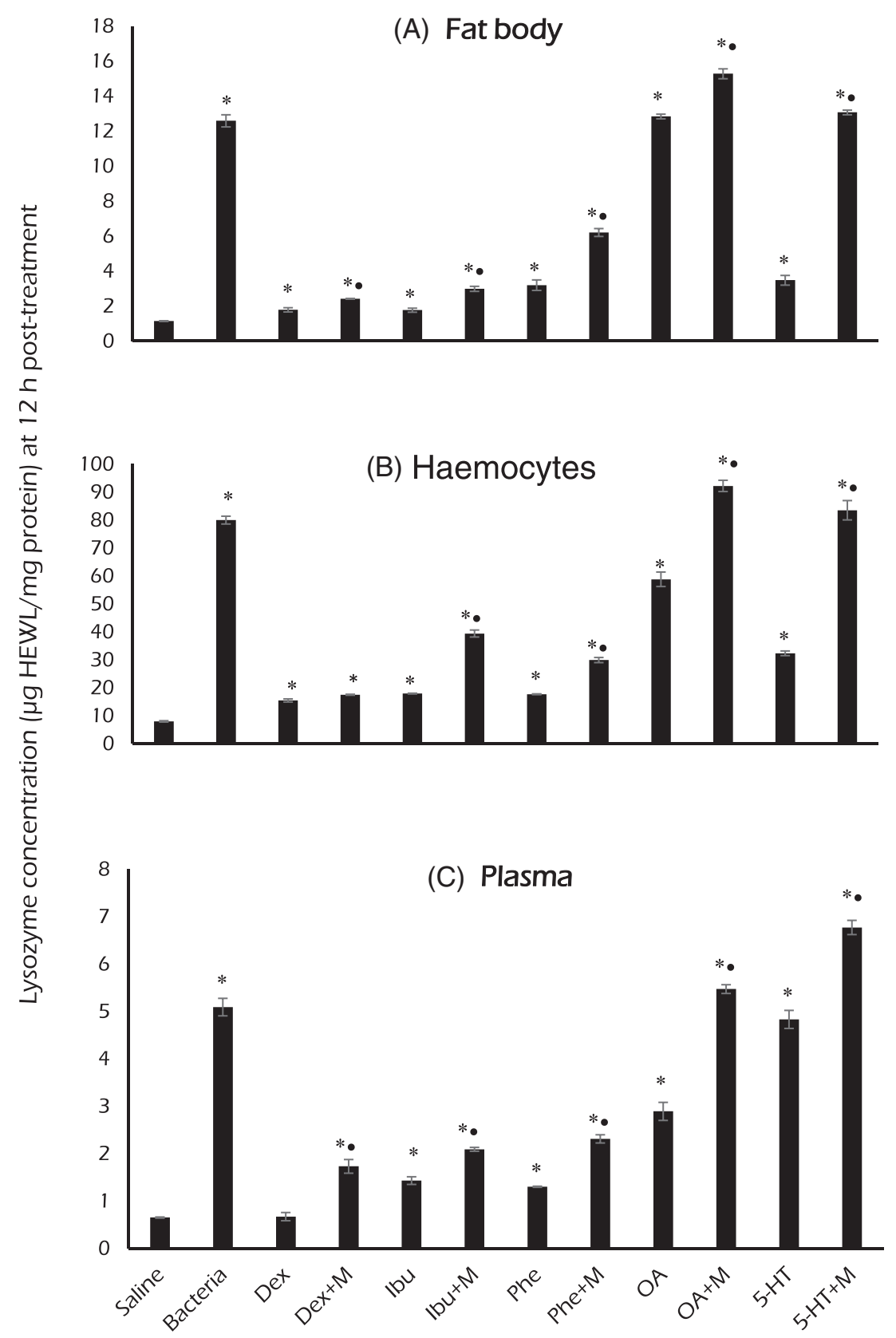

Fig. 2. Lysozyme concentrations, expressed as $\mu \mathrm{g}$ HEWL/mg protein, in (A) fat body, (B) haemocytes and (C) plasma of third instar Sarcophaga argyrostoma post-injection with the Micrococcus luteus, either alone or in couple with an EBI (Dex, Ibu or Phe) or with a BMA (OA or 5-HT) at $12 \mathrm{~h}$ PI. Values are presented as mean $\pm \mathrm{SE}(n=3)$. *significant differences in comparison with the saline-injected larvae at $P<0.05$; 'significant differences in comparison to the corresponding group of the larvae treated with chemical alone.

NO concentration compared to treatment with either one alone. The highest NO concentration was obtained in the haemocytes, followed by plasma and finally fat body in all treatments with either the BMA alone or in combination with M. luteus. Treatment with the BMAs, either alone or in combination with $M$. luteus, induced a significant enhancement in the NO concentration compared to the non-treated larvae (Fig. 1).

The fitting equations of the relationship and correlation coefficients $(r)$ of the experimental times with the different treatment effects on $\mathrm{NO}$ in the different tested tissues are given in Appendix S2A. The levels of NO in the third instar 
$S$. argyrostoma after injection of $M$. luteus, EBIs (Dex, Ibu and Phe), or BMAs (OA and 5-HT) were significantly affected by the experimental periods $\left(F_{5,144}=2599 ; P<0.0001, F_{5,144}=877 ; P<0.0001\right.$, $F_{5,144}=892 ; P<0.0001, F_{5,144}=228, P<0.0001$ and $F_{5,144}=812 ; P<0.0001$, respectively). In addition, the type of tissue (fat body, haemocytes and plasma) markedly affected the lysozyme activities after treatment with $\operatorname{Dex}\left(F_{2,144}=470256, P<0.0001\right)$, Ibu $\left(F_{2,144}=167067, P<0.0001\right)$, Phe $\left(F_{2,144}=67849\right.$, $P<0.0001)$, OA $\left(F_{2,144}=24005, P<0.0001\right)$ and 5-HT $\left(F_{2,144}=37271, P<0.0001\right)$ (Appendix S3A).

\section{Lysozymes and modulating actions of EBIs and BMAs}

Comparable to $\mathrm{NO}$ data presentation (selection of a specific data point, $6 \mathrm{~h}$ ), we adopted $12 \mathrm{~h}$ PI data as an optimum biosynthetic time to present the main results of EBIs actions in Lys (Fig. 2) and the whole dataset is given in Appendix S2B.

Lysozyme concentration of the saline-treated $S$. argyrostoma larvae showed a fluctuating pattern with the time PI, while the IrLys concentration in haemocytes, fat body and plasma displayed maximal values after $6,12,12 \mathrm{~h}$ PI, respectively, then decreased gradually with time in case of treatment with M. luteus. The constitutive levels order of lysozyme concentration of non-treated larvae, in a descending order, was haemocytes $>$ fat body $>$ plasma (Appendix S2B).

Similar to NO concentration, lysozyme concentration in S. argyrostoma larvae decreased with the increase in time PI (up to $72 \mathrm{~h}$ ) with the three EBIs studied alone (Dex, Ibu and Phe) or in combination with $M$. luteus in fat body, haemocytes and plasma. Combined treatment significantly enhanced lysozyme concentration compared to the individual treatment (Fig. 2). In all treatments (individual or combined), approximately complete inhibition of the lysozyme concentration was observed up to $48 \mathrm{~h}$ PI with Dex and Phe alone, and up to $72 \mathrm{~h}$ PI, except with Dex combined with $M$. luteus. The highest concentration was recorded from haemocytes, followed by the fat body, and finally the plasma (Fig. 2). The same trend was present in larvae treated with the two BMAs (OA and 5-HT) alone or in combination with M. luteus (Fig. 2). However, no complete inhibition of lysozyme concentration was recorded up to the end of the experimental period, i.e. $72 \mathrm{~h}$ PI. Maximum lysozyme concentration was observed in the haemocytes while minimum was observed in plasma. Larvae treated with either EBIs, BMAs or $M$. luteus either alone or in combination showed a significant increase in the lysozyme concentration compared to the control larvae (Fig. 2).

The fitting equations of the relationship and correlation coefficients $(r)$ of the experimental times with the different treatment effects on lysozyme biosynthesis in the different tested tissues are given in Appendix S2B. The lysozyme activity in the third instar S. argyrostoma after injection of $M$. luteus, EBIs (Dex, Ibu, and Phe), or the BMAs (OA and 5HT) were significantly affected by the experimental periods $\left(F_{5,144}=528.8 ; P<0.0001, F_{5,144}=308.1\right.$; $P<0.0001, F_{5,144}=375 ; P<0.0001, F_{5,144}=187.8$, $P<0.0001$ and $F_{5,144}=162.6 ; P<0.0001$, respectively). In addition, the type of tissue (fat body, haemocytes and plasma) markedly affected the lysozyme activities after treatment with $\operatorname{Dex}\left(F_{2,144}=2275.5\right.$, $P<0.0001)$, Ibu $\left(F_{2,144}=1856.2, P<0.0001\right)$, Phe $\left(F_{2,144}=1980.9, P<0.0001\right)$, OA $\left(F_{2,144}=2835.1\right.$, $P<0.0001)$ and 5-HT $\left(F_{2,144}=2019.5, P<0.0001\right)$ (Appendix S3B).

\section{Discussion}

NO plays various roles in insect immunity; perhaps as a cytotoxic component and also as a nitrinergic signal molecule (Müller, 1997; Alderton et al., 2001). In this study, the de novo production of NO suggests that it is an immune response molecule against bacteria that is mainly biosynthesized in haemocytes compared to fat body, if the rates of NO release from the two tissues into haemolymph are equal, but that remains to be confirmed. For the dipteran A. gambiae, Hillyer and Estévez-Lao (2009) reported a fat body-haemocyte comparison that agrees with the data presented in this study. The haemocytes appear to express more iNOS than fat body.

Our data show a constitutive level of lysozyme and IrLys concentrations in larvae, which were increased in immune-challenged larvae. The plasma constitutive lysozymes perform the early immune responses against the invading bacteria by degrading bacterial cells and debris (Park et al., 1997) and releasing fragments of PGN, a key-step in bacterial pattern recognition (Imler and Bulet, 2005). Gillespie et al. (1993) ascribed the lysozyme activity of crude haemolymph preparations to its ability to lyse cell walls of M. lysodeikticus. This bacterium is highly sensitive to lysozymes that preferentially hydrolyse its mucopeptide cell-wall structure (Kocur et al., 1972; Jenzano et al., 1986); and hence, it is widely used in routine screening of antibacterial lysozyme activity. IrLys activity was evident in other insects at $6 \mathrm{~h} \mathrm{PI}$, and reached a maximum at $48 \mathrm{~h}$ PI and then declined slightly (Abraham et al., 1995; Kim and Yoe, 2003). In larval S. argyrostoma, haemocytes and fat body biosynthesize IrLys de novo. Haemocytes produced and stored IrLy than fat body, probably for both biosynthesis and storage, as reported in other insects, including R. prolixus (Azambuja et al., 1999) and Manduca sexta (Rao and Yu, 2011). In these cases, use of concentration criterion for comparison is valid only if the rates of release of lysozyme from 
these two tissues are equal. In third instar Drosophila, a subepidermal population of sessile haemocytes was observed to be released into the circulation in response to parasitization. These sessile haemocytes are a novel haematopoietic tissue that constitutes the main source of certain blood cells (Márkus et al., 2009; Leitão and Sucena, 2015). It is likely that sessile haemocytes were present in the isolated fat body, which would contribute to the activities that were observed in that tissue. Sessile haemocytes are perhaps not a major factor, but a factor nonetheless.

A potential crosstalk may exist between the signalling cascades regulating both IrLys biosynthesis and NO production (and perhaps each with other humoral immune effectors). For instance, lysozymes can intrinsically stimulate production of $\mathrm{H}_{2} \mathrm{O}_{2}$, which in turn activates $\mathrm{H}_{2} \mathrm{O}_{2}$-dependent pathways leading to upregulation of iNOS and formation of NO (Mink et al., 2009). Likewise, LPS-stimulated macrophages showed enhanced phagocytosis and NO, lysozyme and PGE2 biosynthesis (Qin et al., 2001).

In the present study, eicosanoids and certain BMAs acted as immune mediators in larval $S$. argyrostoma. EBI treatments led to suppression of $\mathrm{NO}$ and lysozymes post-bacterial challenge, when each EBI was injected with $M$. luteus. We infer that eicosanoids act in mediating and coordinating biosynthesis of iNOS and lysozyme. A few studies are available on eicosanoid mediation of lysozyme immune response in insects, e.g. in Bombyx mori, D. melanogaster, and Spodoptera exigua (Morishima et al., 1997; Yajima et al., 2003; Shrestha and Kim, 2009). There are no reports of eicosanoids mediating $\mathrm{NO}$ metabolism and its role in insect immunity. However, injection of the larval S. argyrostoma with any of the EBIs-Dex, Ibu or Phe-caused elevation of lysozyme concentration over the level of the saline-injected controls. Similar results were reported before in other insects, e.g. for nodulation and phenoloxidase activity in Pimpla turionellae by the EBI esculetin (Durmus et al., 2008). Dex failed to inhibit the increase of haemocyte population of bacteria-injected S. exigua (Kim and Kim, 2010).

A noteworthy problem with using pharmaceutical inhibitors to test biochemical pathways is the likelihood of non-specific or non-physiological impacts (Stanley Samuelson et al., 1991). This shortcoming has been addressed by generating doseresponse curves, showing that EBIs act in a doserelated manner (Miller et al., 1994; Srikanth et al., 2011). This indicates the EBIs acted in a physiological, rather than pharmaceutical, mechanism. The linear negative relationships we obtained for EBIs, in particular, support the idea that eicosanoids mediate the tested immune reactions to bacterial infections in flesh flies. Dex is a glucocorticosteroid that inhibits PLA2 specifically. It binds to certain nuclear steroid receptors and interferes with NF$\kappa \mathrm{B}$ activation and apoptotic pathways (Yamamoto and Gaynor, 2001). Dex down regulates the expression of several inflammation-regulatory genes and has immunosuppressive properties. For the other two pharmaceutical inhibitors, Phe binds to and inhibits the enzymatic activity of LOXs and reduces the production of leukotrines. Also, it combines with COX, and thereby, prevents its substrateenzyme combination with AA and the formation of eicosanoids, PGs and thromboxanes. While on the contrary, Ibu is a nonsteroidal anti-inflammatory agent with pharmacologic actions thought to act through inhibition of PGs synthesis by inhibiting COXs, which converts AA to cyclic endoperoxides, precursors of PGs (Stanley and Kim, 2014). Because these chemicals suppressed the levels of both IrLys and NO, we suggest that their actions may be accomplished by inhibiting the AA cascade in $S$. argyrostoma.

In Drosophila, PLA2 is involved in the LPSdependent activation of the immune deficiency pathway (imd), an equivalent to the NF- $\kappa$ B signalling pathway in mammals, via stimulation of AA and other mediators. Dex inhibits this imdLPS-dependent activation; thus, a certain crosstalk exists between the PLA2-generated AA cascade and the LPS-stimulated imd pathway in insect immunity (Yajima et al., 2003). In S. exigua, the plasmatocyte-spreading peptide acts via biosynthesis of eicosanoids, where PLA2 inhibitors reversibly block plasmatocyte spreading (Srikanth et al., 2011). It is also possible that eicosanoid signalling concatenate with other cellular/humoral process mediators (such as BMAs), in insect immunity.

We investigated the actions of BMAs in the present work. These compounds act as neurotransmitters, neuromodulators in response to acute stress and neurohormones in the insect nervous system (Roeder, 2005). Co-injection of OA or 5HT (a serotonin receptor agonist) with $M$. luteus elevated NO concentrations in haemocytes and fat body. However, OA, but not 5-HT, elevated IrLys concentrations in haemocytes and fat body. Hence, $\mathrm{OA}$ affects the $S$. argyrostoma IrLys responses and may mediate other stress responses. The immuneenhancing action of OA was reported earlier (Brey, 1994). It can also boost resistance to infection when co-incubated with the pathogen (Baines et al., 1992; Baines and Downer, 1994). Following LPS activation, Pieris rapae haemocytes synthesize elevated levels of 5-HT in a dose-dependent manner (Qi et al., 2016). In mollusc haemocytes, NE (analogous to OA) enhances the LPS-induced production of NO, a process that is regulated via a $\alpha / \beta$-adrenoceptorcAMP $/ \mathrm{Ca}^{2+}$ pathway. NO exerts a reversible feedback homeostatic action on the biosynthesis of NE (Jiang et al., 2014). OA concurrently adapts the insect 
immune system to maintain maximal functioning under fluctuating physiological conditions (Adamo, 2008). Hence, we suggest that injection of OA alone, and similarly 5-HT, may augment the background tissue levels of both NO and IrLys in response to injection stress in the larvae. The latter observation may be supported by pronounced expression of $5-\mathrm{HT}$, for example, by naïve haemocytes in some insects (Qi et al., 2016).

BMAs act via cell surface receptors, which leads to increased concentrations of intracellular second messengers, such as cAMP and inositol triphosphate, as seen in Periplaneta americana (Orr et al., 1985; Baines and Downer, 1994), cAMP in D. melanogaster (Williams et al., 2006), Galleria mellonella (Marin et al., 2005), and S. exigua (Kim and Kim, 2010) and $\mathrm{Ca}^{2+}$ in Chilo suppressalis (Huang et al., 2012). Furthermore, OA and 5-HT are pleiotropic and implicated in various physiological processes and behaviours. These biogenic amines could be acting via the modulation of dorsal vessel physiology. Both OA in Apis mellifera and Bactrocera oleae (Papaefthimiou and Theophilidis, 2011) and 5HT in A. gambiae (Hillyer et al., 2015) are cardioacceleratory, known to increase the heart rate. This would increase haemolymph flow, perhaps increasing the dissemination and delivery of the tested antimicrobial factors. We suspect similar mechanisms operate in larval S. argyrostoma, the subject of future work.

\section{Conclusion}

The observation that EBIs retard the activities of iNO and irLys in flesh fly larvae indicate that their actions are exerted through a common mechanism; specifically, inhibition of COXs. Accordingly, eicosanoids act in biosynthesis of NO and lysozymes. Nonetheless, BMAs enhance flesh fly immunity. We interpret this finding in terms of immune-reactive activities. However, understanding the molecular regulatory mechanisms underlying the modulation of eicosanoid and biogenic amines to the targeted genes should provide strong evidence on the interactions and pleiotropic actions of these molecules in the cell.

\section{Future perspective}

As a part of ongoing research, we identified four different mRNA sequences coding for ctype lysozymes from the transcriptome shotgun assembly database for the sister flesh fly Sarcophaga (Liopygia) crassipalpis using TBLASTN on NCBI with Lucilia cuprina c-type lysozyme (KNC28071.1). We aim to study their structural and expressional variation in response to immune challenge and the modulation of their expression dynamics by different EBI treatments.

\section{Acknowledgements}

We are grateful to Prof. David Stanley (USDA/Agricultural Research Service, MO, USA) for providing many comments/inputs on the draft of this paper. Thanks are also due to Dr Magdi El-Hawagry for helping in fly identification. We gratefully acknowledge the sincere help of Dr Atef A. Ali in statistical analyses.

\section{Supplementary material}

To view supplementary material for this article, please visit https://doi.org/10.1017/ S1742758417000315

\section{References}

Abraham E. G., Nagaraju J., Salunke D. M., Gupta H. M. and Datta R. K. (1995) Purification and partial characterization of an induced antibacterial protein in the silkworm, Bombyx mori. Journal of Invertebrate Pathology $65,17-24$.

Adamo S. A. (2008) Norepinephrine and octopamine: linking stress and immune function across phyla. Invertebrate Survival Journal 5, 12-19.

Ajjuri R. R. and O'Donnell J. M. (2013) Novel wholetissue quantitative assay of nitric oxide levels in Drosophila neuroinflammatory response. Journal of Visualized Experiments 82, 50892.

Alderton W. K., Cooper C. E. and Knowles R. G. (2001) Nitric oxide synthases: structure, function and inhibition. Biochemical Journal 357, 593-615.

Azambuja P., Feder D., Mello C. B., Gomes S. A. O. and Garcia E.S. (1999) Immunity in Rhodnius prolixus: Trypanosomatid-vector interactions. Memórias do Instituto Oswaldo Cruz, Rio de Janeiro 94, Suppl I, S219-S222.

Baines D. and Downer R.G.H. (1994) Octopamine enhances phagocytosis in cockroach hemocytes: involvement of inositol triphosphate. Archives of Insect Biochemistry and Physiology 26, 249-261.

Baines D., Desantis T. and Downer R. G. H. (1992) Octopamine and 5-hydroxy trypamine enhance the phagocytic and nodule formation activities of cockroach (Periplaneta americana) hemocytes. Journal of Insect Physiology 38, 905-914.

Bradford M. M. (1976) A rapid and sensitive method for the quantitation of microgram quantities of protein utilizing the principle of protein-dye binding. Analytical Biochemistry 72, 248-254.

Brey P. T. (1994) The impact of stress on insect immunity. Bulletin de I'Institut Pasteur 92, 101-118.

Colasanti M., Gradoni L., Mattu M., Persichini T., Salvati L., Venturini G. and Ascenzi P. (2002) Molecular basis 
for the anti-parasitic effect of NO. International Journal of Molecular Medicine 9, 131-134.

Dunphy G. B. and Downer R. G. H. (1994) Octopamine, a modulator of the haemocytic nodulation response of non-immune Galleria mellonella larvae. Journal of Insect Physiology 40, 267-272.

Durmus Y., Büyükgüzel E., Terzi B., Tunaz H., Stanley D. and Büyükgüzel K. (2008) Eicosanoids mediate melanotic nodulation reactions to viral infection in larvae of the parasitic wasp, Pimpla turionellae. Journal of Insect Physiology 54, 17-24.

Faraldo A. C., Sá-Nunes A., Del Bel E. A., Faccioli L. H. and Lello E. (2005) Nitric oxide production in blowfly hemolymph after yeast inoculation. Nitric Oxide 13, 196-203.

Finney D. J. (1971) Probit Analysis 3rd edn. Cambridge. University Press, New York. 333 pp.

Foley E. and O'Farrell P. H. (2003) Nitric oxide contributes to induction of innate immune responses to Gramnegative bacteria in Drosophila. Genes $\mathcal{E}$ Development 17, 115-125.

Gillespie J. P., Kanost M. R. and Trenczek T. (1997) Biological mediators of insect immunity. Annual Review of Entomology 42, 611-643.

Gillespie J. P., Koshinsky H. A. and Khachatourians G. G. (1993) The occurrence of inducible anti-Escherichia coli activity in hemolymph from the migratory grasshopper, Melanoplus sanguinipes. Comparative Biochemistry and Physiology - Part C 104, 111-115.

Grassberger M. and Reiter C. (2002) Effect of temperature on development of Liopygia (= Sarcophaga) argyrostoma (Robineau-Desvoidy) (Diptera: Sarcophagidae) and its forensic implications. Journal of Forensic Sciences 47, 1332-1336.

Green L. C., Wagner D. A., Glogowski J., Skipper P. L., Wishnok J. S. and Tannenbaum S. R. (1982) Analysis of nitrate, nitrite, and $\left[{ }^{15} \mathrm{~N}\right]$ nitrate in biological fluids. Analytical Biochemistry 126, 131-138.

Halliwell B. and Gutteridge J. M. C. (1999) Free radicals, other reactive species and disease, pp. 617-783. In Free Radicals in Biology and Medicine 3rd edn. (edited by B. Halliwell and J. M. C. Gutteridge). Clarendon Press, Oxford.

Hillyer J. F. (2016) Insect immunology and hematopoiesis. Developmental and Comparative Immunology 58, 102-118.

Hillyer J. F. and Estévez-Lao T. Y. (2009) Nitric oxide is an essential component of the hemocyte-mediated mosquito immune response against bacteria. Developmental and Comparative Immunology 34, 141-149.

Hillyer J. F., Estévez-Lao T. Y. and Mirzai H. E. (2015) The neurotransmitters serotonin and glutamate accelerate the heart rate of the mosquito Anopheles gambiae. Comparative Biochemistry and Physiology - Part A 188, 49-57.

Hogg N., Darley-Usmar V. M., Wilson M. T. and Moncada S. (1992) Production of hydroxyl radicals from the simultaneous generation of superoxide and nitric oxide. Biochemical Journal 281, 419-424.
Huang J., Wu S.F., Li X. H., Adamo S. A. and Ye G. Y. (2012) The characterization of a concentrationsensitive $\alpha$-adrenergic-like octopamine receptor found on insect immune cells and its possible role in mediating stress hormone effects on immune function. Brain, Behavior, and Immunity 26, 942-950.

Imler J. L. and Bulet P. (2005) Antimicrobial peptides in Drosophila: structures, activities and gene regulation, vol. 86, pp. 1-21. In Mechanisms of Epithelial Defense (edited by D. Kabelitz and J.M. Schroder). Karger, Basel.

Jenzano J. W., Hogan S. L. and Lundblad R. L. (1986) Factors influencing measurement of human salivary lysozyme in lysoplate and turbidimetric assays. Journal of Clinical Microbiology 24, 963-967.

Jiang Q., Zhou Z., Wang L., Yang C., Wang J., Wu T. and Song L. (2014) Mutual modulation between norepinephrine and nitric oxide in haemocytes during the mollusc immune response. Scientific Reports 4, 6963.

Kim G. S. and Kim Y. (2010) Up-regulation of circulating hemocyte population in response to bacterial challenge is mediated by octopamine and 5hydroxytryptamine via Rac1 signal in Spodoptera exigua. Journal of Insect Physiology 56, 559-566.

Kim G. S., Nalini M., Kim Y. and Lee D. W. (2009) Octopamine and 5-hydroxytryptamine mediate hemocytic phagocytosis and nodule formation via eicosanoids in the beet armyworm, Spodoptera exigua. Archives of Insect Biochemistry and Physiology 70, 162-176.

Kim J. W. and Yoe S. M. (2003) Purification of lysozyme from hemolymph of tobacco cutworm, Spodoptera litura. Korean Journal of Entomology 33, 287-291.

Kocur M., Pačova Z. and Martinec T. (1972) Taxonomic status of Micrococcus luteus (Schroeter 1872) Cohn 1872, and designation of the neotype strain. International Journal of Systematic and Evolutionary Microbiology 22, 218-223.

Leitão A. B. and Sucena É. (2015) Drosophila sessile hemocyte clusters are true hematopoietic tissues that regulate larval blood cell differentiation. eLife 4, e06166.

Leonard C., Söderhäll K. and Ratcliffe N. A. (1985) Studies on prophenoloxidase and protease activity of Blaberus craniifer haemocytes. Insect Biochemistry 15, 803-810.

Luckhart S., Vodovotz Y., Cui L. and Rosenberg R. (1998) The mosquito Anopheles stephensi limits malaria parasite development with inducible synthesis of nitric oxide. Proceedings of the National Academy of Sciences USA 95, 5700-5705.

Marin D., Dunphy G. B. and Mandato C. A. (2005) Cyclic AMP affects the haemocyte responses of larval Galleria mellonella to selected antigens. Journal of Insect Physiology 51, 575-586.

Márkus R., Laurinyecz B., Kurucz É., Honti V., Bajusz I., Sipos B., Somogyi K., Kronhamn J., Hultmark D. and Andó I. (2009) Sessile hemocytes as a hematopoietic compartment in Drosophila melanogaster. 
Proceedings of the National Academy of Sciences USA 106, 4805-4809.

Miller J. S., Nguyen T. and Stanley-Samuelson D. W. (1994) Eicosanoids mediate insect nodulation responses to bacterial infections. Proceedings of the National Academy of Sciences USA 91, 12418-12422.

Mink S. N., Jacobs H., Cheng Z. Q., Kasian K., SantosMartinez L. E. and Light R. B. (2009) Lysozyme, a mediator of sepsis that intrinsically generates hydrogen peroxide to cause cardiovascular dysfunction. American Journal of Physiology, Heart and Circulatory Physiology 297, H930-H948.

Mohamed A. A., Elmogy M., Dorrah M. A., Yousef H. A. and Bassal T. T. M. (2013) Antibacterial activity of lysozyme in the desert locust, Schistocerca gregaria (Orthoptera: Acrididae). European Journal of Entomology 110, 559-565.

Mohamed A. A., Zhang L., Dorrah M. A., Elmogy M., Yousef H. A., Bassal T. T. and Duvic B. (2016) Molecular characterization of a c-type lysozyme from the desert locust, Schistocerca gregaria (Orthoptera: Acrididae). Developmental and Comparative Immunology 61, 60-69.

Morishima I., Horiba T., Iketami M., Nishioka E. and Yamano Y. (1995) Parallel induction of cecropin and lysozyme in larvae of the silkworm Bombyx mori. Developmental and Comparative Immunology 19, 357-363.

Morishima I., Yamano Y., Inoue K. and Matsuo N. (1997) Eicosanoids mediate induction of immune genes in the fat body of the silkworm, Bombyx mori. FEBS Letters $419,83-86$.

Müller U. (1997) The nitric oxide system in insects. Progress in Neurobiology 51, 363-381.

Nappi A. J., Vass E., Frey F. and Carton Y. (2000) Nitric oxide involvement in Drosophila immunity. Nitric Oxide 4, 423-430.

Orr G. L., Gole J. W. D. and Downer R. G. H. (1985) Characterization of an octopamine-sensitive adenylate cyclase in hemocyte membrane fragments of the American cockroach Periplaneta americana L. Insect Biochemistry 15, 695-701.

Papaefthimiou C. and Theophilidis G. (2011) Octopamine-a single modulator with double action on the heart of two insect species (Apis mellifera macedonica and Bactrocera oleae): Acceleration vs. inhibition. Journal of Insect Physiology 57, 316-325.

Park H. Y., Park S. S., Shin S. W., Park D. S., Kim M. G., Oh H. W. and Joo C. K. (1997) Protein purification and nucleotide sequence of a lysozyme from the bacteriainduced larvae of the fall webworm, Hyphantria cunea. Archives of Insect Biochemistry and Physiology 35, 335345.

Peeters T. L. and Vantrappen G. R. (1977) Factors influencing lysozyme determinations by the lysoplate method. Clinica Chimica Acta 74, 217-225.

Prescott L. M., Harley J. P. and Klein D. A. (1993) Microbiology 2nd edn. Wm. C. Brown Communications, Dubuque, Iowa. 55 pp.
Qi Y. X., Huang J., Li M. Q., Wu Y.S., Xia R. Y. and Ye G. Y. (2016) Serotonin modulates insect hemocyte phagocytosis via two different serotonin receptors. eLife 5, e12241.

Qin Q. W., Ototake M., Noguchi K., Soma G., Yokomizo Y. and Nakanishi T. (2001) Tumor necrosis factor alpha (TNFalpha)-like factor produced by macrophages in rainbow trout, Oncorhynchus mykiss. Fish and Shellfish Immunology 11, 245-256.

Rao X. and Yu X. (2011) Lipoteichoic acid and lipopolysaccharide can activate antimicrobial peptide expression in the tobacco hornworm Manduca sexta. Developmental and Comparative Immunology 34, 1119-1128.

Roeder T. (2005) Tyramine and octopamine: ruling behavior and metabolism. Annual Review of Entomology $50,447-477$.

Shrestha S. and Kim Y. (2008) Eicosanoids mediate prophenoloxidase release from oenocytoids in the beet armyworm Spodoptera exigua. Insect Biochemistry and Molecular Biology 38, 99-112.

Shrestha S. and Kim Y. (2009) Various eicosanoids modulate the cellular and humoral immune responses of the beet armyworm, Spodoptera exigua. Bioscience, Biotechnology, and Biochemistry 73, 2077-2084.

Shrestha S., Park J., Ahn S.-J. and Kim Y. (2015) PGE2 mediates oenocytoid cell lysis via a sodiumpotassium-chloride cotransporter. Archives of Insect Biochemistry and Physiology 89, 218-229.

Söderhäll K. and Smith V. J. (1983) Separation of the hemocyte populations of Carcinus maenas and other marine decapods, and prophenoloxidase distribution. Developmental and Comparative Immunology 7, 229-239.

Srikanth K., Park J., Stanley D. W. and Kim Y. (2011) Plasmatocyte-spreading peptide influences hemocyte behavior via eicosanoids. Archives of Insect Biochemistry and Physiology 78, 145-160.

Stanley D. W. (2000) Eicosanoids in Invertebrate Signal Transduction Systems. Princeton University Press, Princeton, NJ.

Stanley D. W. and Kim Y. (2014) Eicosanoid signaling in insects: from discovery to plant protection. Critical Reviews in Plant Sciences 33, 20-63.

Stanley-Samuelson D. W., Jensen E., Nickerson K. W., Tiebel K., Ogg C. L. and Howard R. W. (1991) Insect immune response to bacterial infection is mediated by eicosanoids. Proceedings of the National Academy of Sciences USA 88, 1064-1068.

Vilcinskas A. and Matha V. (1997) Antimycotic activity of lysozyme and its contribution to antifungal humoral defense reactions in Galleria mellonella. Animal Biology 6, 19-29.

Wasserman S. L. and Itagaki H. (2003) The olfactory responses of the antenna and maxillary palp of the fleshfly, Neobellieria bullata (Diptera: Sarcophagidae), and their sensitivity to blockage of nitric oxide synthase. Journal of Insect Physiology 49, 271-280.

Whitten M. M., Mello C. B., Gomes S. A., Nigam Y., Azambuja P., Garcia E. S. and Ratcliffe N. A. (2001) 
Role of superoxide and reactive nitrogen intermediates in Rhodnius prolixus (Reduviidae)/Trypanosoma rangeli interactions. Experimental Parasitology 98, 44-57.

Williams M., Wiklund M.-L., Wikman S. and Hultmark D. (2006) Rac1 signalling in the Drosophila larval cellular immune response. Journal of Cell Science 119, 20152024.

Yajima M., Takada M., Takahashi N., Kikuchi H., Natori S., Oshima Y. and Kurata S. (2003) A newly established in vitro culture using transgenic Drosophila reveals functional coupling between the phospholipase A2generated fatty acid cascade and lipopolysaccharidedependent activation of the immune deficiency (IMD) pathway in insect immunity. Biochemical Journal 371, 205-210.

Yamamoto Y. and Gaynor R. B. (2001) Therapeutic potential of inhibition of the NF- $\kappa \mathrm{B}$ pathway in the treatment of inflammation and cancer. Journal of Clinical Investigation 107, 135142. 